\section{Pollution threatens toothed whales}

In their Report "Ancient convergent losses of Paraoxonase 1 yield potential risks for modern marine mammals" (10 August, p. 591), W. K. Meyer et al. show that marine mammals are particularly vulnerable to adverse health effects from organophosphorus pesticide pollution because of a functional loss of the primary mammalian metabolic defense mechanism-the Paraoxonase 1 gene. Unfortunately, this finding is just one example of an evolutionary deficiency that puts marine mammals at increased risk for modern-day pollution.

Toothed whales, which originated in the mid-Eocene from herbivorous artiodactyls (cloven-hooved land mammal) (1), also show a reduced metabolic ability to eliminate persistent environmental pollutants such as biomagnifiable polychlorinated biphenyls (PCBs) compared with carnivorous predators such as polar bears (Ursus maritimus), seals and walruses, and humans (2, 3). Because they lack the ability to filter these chemicals, extreme concentrations of PCBs and mercury have been found in high trophic-feeding cetaceans, including killer whales (Orcinus orca) (4, 5). Moreover, toothed whales lack the keratinous pollutant sequestration routes, such as hair, that relieve carnivorous marine mammals from their contaminant burden including mercury (5).

Given the vulnerability of marine mammals, global regulation and remediation of harmful marine pollutants, including organophosphorus compounds and PCBs, should be urgently prioritized by the United Nations Environment Programme, the Stockholm Convention, and the U.S. Environmental Protection Agency (6, 7). Failing to protect these cetaceans could lead to pollution-mediated population collapses $(8,9)$ and an irreversible loss of biodiversity and ecosystem services.

\footnotetext{
Christian Sonne, ${ }^{1}$ * Paul D.

Jepson, ${ }^{2}$ Jean-Pierre Desforges, ${ }^{1}$ Aage $K$. O. Alstrup, ${ }^{3}$ Morten $T$.

sciencemag.org

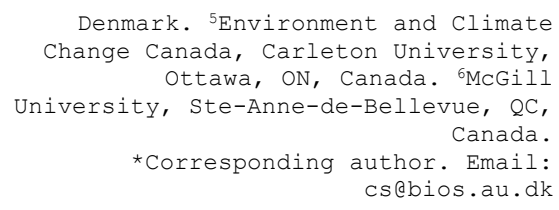

Denmark. ${ }^{5}$ Environment and Climate Change Canada, Carleton University, Ottawa, ON, Canada. ${ }^{6} \mathrm{McGill}$ University, Ste-Anne-de-Bellevue, QC, Canada. *Corresponding author. Email: csebios.au.dk

REFERENCES

1. J. G. M. Thewissen et al., Nature 450, 20 (2007).

2. M. A. McKinney et al., Environ. Toxicol. Chem. 30, 7 (2011). 3. S. Kim et al., Genome Biol. 17, 211 (2016).

4. R. J. Letcher et al., Sci. Total Environ. 408, 2995-3043xxxx (2010).

5. R. Dietz et al., Sci. Total Environ. 443,775-790 (2013).

6. A. M. Milner, I. L. Boyd, Science 357, 1232 (2017).

7. R. J. Law, P. D. Jepson, Science 356, 148 (2017).

8. P. D. Jepson, R.J. Law, Science 352, 1388 (2016).

9. P. D. Jepson etal., Sci. Rep. 6, 18573 (2016).

10.1126/science.aav2403 